Simple Heuristics: The Foundations of Adaptive Social Behavior

University Press Scholarship Online

Oxford Scholarship Online

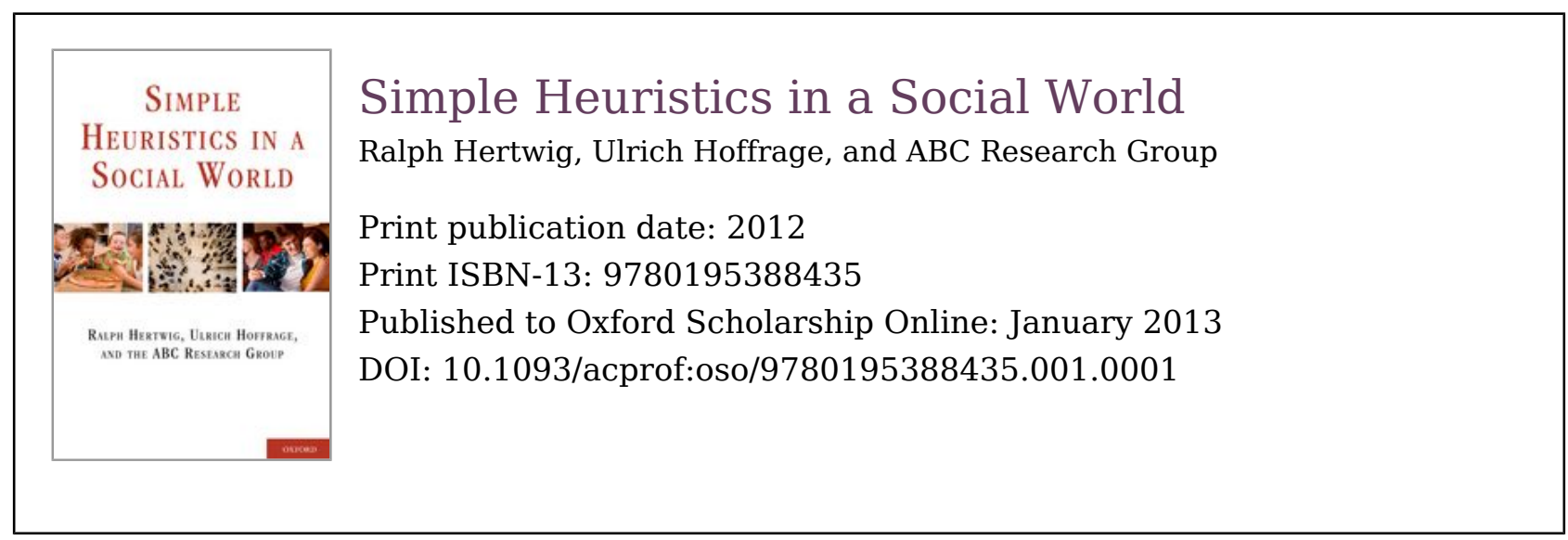

\title{
Simple Heuristics: The Foundations of Adaptive Social Behavior
}

\author{
Ralph Hertwig
}

Ulrich Hoffrage

DOI:10.1093/acprof:oso/9780195388435.003.0001

\section{Abstract and Keywords}

This chapter shows how simple heuristics can be an essential tool for navigating the complexities and vagaries of social environments. The research program on the nature of social rationality presented here can be summarized by the following theses: As perceived by the human mind, the social world (Umwelt) is complex, but not necessarily more complex than the nonsocial world. However complex the social world may be, its complexity does not require cognitive complexity; rather, it entails conditions that make simple heuristics indispensible, such as intractability, multiple competing goals, and incommensurable reasons. Much of reasoning and decision making occurring in human and animal social environments can be modeled in terms of simple heuristics. Although simple heuristics forgo extensive information search and complex calculations, they can be as accurate and even 
more accurate than more complex strategies and/or can be used to reach other goals that are valued in social environments (e.g., transparency, fairness, speed). Heuristics can be simultaneously successful and simple by coopting evolved capacities. The capacities themselves can represent complex adaptive specializations (e.g., memory, movement tracking). Simple heuristics per se are neither rational nor irrational. Their rationality is ecological. That is, their performance depends on the match between the architecture of the heuristic and the structure of the environment in which it is used. The heuristics' simplicity inoculates them against overfitting and enables them to achieve robust performance given small samples of information. Simple heuristics can model adaptive decision making both in games against nature and in social games. There is no social intelligence distinct from nonsocial intelligence. Simple heuristics are tools of moderate generalizability. Some can be used only in games against nature, whereas others are restricted to social games. Still other heuristics can be applied in both types of games. Shedding light on the adaptive toolbox of simple heuristics used to navigate social environments, and characterizing their strengths and weaknesses, can help us design environments and/or heuristics in ways that improve public welfare.

Keywords: social rationality, ecological rationality, bounded rationality, heuristics, complexity, robustness, adaptive toolbox, social learning, social intelligence, optimization

Human beings viewed as behaving systems are quite simple. The apparent complexity of our behavior over time is largely a reflection of the complexity of the environment in which we find ourselves.

\section{Herbert A. Simon ( 1996 )}

Arguably the most revered president of the United States was its first, George Washington. Widely admired for his rectitude, valor, and courteousness (Alden, 1984), Washington's character and inclinations were already evident at a young age. As a schoolboy growing up in eighteenth-century Virginia - possibly as an exercise in penmanship-he copied out by hand a set of maxims called 110 Rules of Civility and Decent

\footnotetext{
Page 2 of 44
} 
Behavior in Company and Conversation (Selzer, 2000). French Jesuits compiled these maxims in the sixteenth century for the edification of young gentlemen. According to many of his biographers, the 110 Rules had a profound influence on Washington ("New light on the youth of Washington," 1904). Most of them concern matters of etiquette, such as table manners, comportment during conversation, and proper dressing. Rule 6 of decent behavior, for instance, instructs: "Sleep not when others speak, sit not when others stand, speak not when you should hold your peace, walk not on when others stop" (Selzer, 2000, p. 13).

Some of the rules, however, are more than the French Jesuits' answer to Miss Manners (Martin, 2005). Some are simple strategies, or heuristics, that help the user navigate potentially perilous social situations. For illustration, take the question of how to behave in disputes. One of the most prevalent types of homicide in Washington's day (like today) was not premeditated murder, but rather deadly violence triggered by the most trivial of circumstances. Such violence has been observed across many social milieus and historical (p.4) epochs, from Oxford in the thirteenth and fourteenth centuries to Miami in the twentieth century (see Daly \& Wilson, 1988). To illustrate the lethal potential of a seemingly inconsequential altercation in medieval Oxford, historian Hammer (1978) described the death of an Irish student thus: "[He] was killed in a tavern brawl after a dispute arose between two groups of students. Thus, sharp tongues, quick tempers and strong drinks often seem to have been a fatal combination" (p. 20). In light of the peril arising from threats to a male's social status and reputation in a "culture of honor" (Nisbett \& Cohen, 1996), it is not surprising that some of the rules of civility that Washington held in such high regard concerned how to behave in debates and disputes. One such heuristic counsels the witness to an argument to steer clear of difficulties by adopting the following policy:

Rule 69: If two contend together, take not the part of either unconstrained, and be not obstinate in your own 
opinion. In things indifferent be of the major side.

(Selzer, 2000, p. 96; emphasis added)

By counseling alignment with the majority in the absence of a strong personal opinion, the heuristic thus tells the bystander to ignore information such as the social status, reputation, and intellectual credentials of the contenders. Another of the 110 Rules, applicable when a person finds himself involved in a dispute, likewise emphasizes the importance of majority opinion:

Rule 86: In dispute be not so desirous to overcome as not to give liberty to each one to deliver his opinion and submit to the judgement of the major part, especially if they are judges of the dispute. (Selzer, 2000, p. 115; emphasis added)

The building block that these heuristics have in common is reliance on the actions of the majority of one's peers as a guide to appropriate behavior and decision making. Indeed, imitating, copying, and benefiting from the opinions, attitudes, appearance, or-more generally-the behavior of others is one important form of bounded rationality (Simon, 1982) in the social world.

\section{Heuristics in a Social World}

Research on bounded rationality aims to describe how decision-making agents in the real world arrive at their inferences, choices, and decisions given realistic amounts of time, information, and computational resources. The vision of bounded rationality espoused in this book speaks in terms of models of simple heuristics; the research (p.5) program grounded in this vision was laid out in Simple Heuristics That Make Us Smart (Gigerenzer, Todd, \& the ABC Research Group, 1999). We advance this program by exploring simple heuristics for making decisions in specifically social environments-that is, environments in which humans and other animals compete with others for myriad resources such as food, mates, esteem, or affection, and in which rivals grant the decision maker little time for deep thought, protracted information search, or complex calculations. The social world, however, also encompasses environments in which others

\footnotetext{
Page 4 of 44
} 
teach us how to deal with a fickle and unstable natural world that inflicts unforeseeable hazards, diseases, and famines; environments in which people forge alliances, cooperate with each other, and work in groups to boost their chances of success; and environments in which people dare to trust others and enforce fair play. In such a complex social world, Homo sapiens can be seen, according to the thesis of the present book, as a Homo heuristicus (Gigerenzer, Hertwig, \& Pachur, 2011), a species that relies heavily on appropriate simple heuristics to get the job of making decisions done. Many definitions of heuristics have been proposed (for an overview, see Gigerenzer \& Gaissmaier, 2011). Here we adopt the following definition:

A heuristic is a strategy that ignores part of the information, with the goal of making decisions more quickly, frugally, and/or accurately than more complex methods. (Gigerenzer \& Gaissmaier, 2011, p. 454)

Heuristics thus depart from classic notions of rationality in economics, psychology and other fields, in which rationality is typically equated with optimization (i.e., maximization or minimization) of some function. For illustration, let us review some key heuristics that have been proposed as being in the mind's adaptive toolbox (Gigerenzer et al., 1999) to aid decision making in a social world.

\section{Learning from Others}

When Harry Potter and the Deathly Hallows, the seventh and final volume of J. K. Rowling's fantasy series about the adventures of a boy wizard, was released in the United States in 2007, it sold 8.3 million copies in its first 24 hours on sale (Miller, 2007). Was the last Harry Potter book that good? Perhaps it and the earlier six volumes were genuinely brilliant -despite the fact that eight publishers declined to publish the first volume, Harry Potter and the Philosopher's Stone (Watts, 2007). But although success is at least partly determined by intrinsic quality, it is also possible that what people come to like depends very much on what they believe others like (Salganik, Dodds, \& Watts, 2006). In such a world, the (p.6) explanation for why a particular book becomes a hit may be as simple as this publisher's: "It sold well because lots of people 
bought it" (Watts, 2007). Because social information is now being shared much more widely across virtual and actual borders than in the past, cultural artifacts such as books and movies can now "snowball" in popularity in ways they could not a century ago, turning cultural commerce into a collection of difficult-to-predict, winner-take-all markets (Frank \& Cook, 1995; Salganik et al., 2006). Tiny differences in performance or product quality translate into vast differences in payoff.

People appear to prefer to experience the same things as others do. What others like or dislike, however, is not only informative when we try to figure out what new clothes, book, mobile phone, or car to buy. People follow others' example in deciding whether to adopt environmentally friendly or "green" behavior (Goldstein, Cialdini, \& Griskevicius, 2008).

Companies imitate one another's successful business models. In the airline industry, for instance, British Airways launched Go, a low-cost airline that emulated Ryanair's no-frills model to compete in the budget air travel market (CasadesusMasanell \& Zhu, 2011). Even literary characters such as Robinson Crusoe are depicted as navigating a hostile, lonely environment-before Friday's arrival-by recalling others' behaviors and imitating it (Defoe, 1719/1815, p. 179). In fact, the ability to imitate others is an elementary building block of human behavior. At just a few days old, babies already show signs of belonging to Homo imitans (Meltzoff, 1988), imitating a range of facial gestures-such as an adult's tongue protrusion (Meltzoff \& Moore, 1977). The ability to imitate also appears key in children's developing understanding of other minds (Meltzoff \& Williamson, 2010). As teenagers and adults, we learn from others' behavior how to engage with tools, cultural artifacts, and technologies, as well as the gestures, postures, and behaviors that define culturally appropriate social interactions. Finally, behavioral mimicry has also been suggested as fostering emotional recognition and empathy (Stel \& van Knippenberg, 2008).

Others are arguably the most important source of a person's knowledge, so individual learning in isolation may be the exception to the rule. The human being, the quintessential social animal, is not alone in showing behavior that is strongly

Page 6 of 44

PRINTED FROM OXFORD SCHOLARSHIP ONLINE (www.oxfordscholarship.com). (c) Copyright Oxford University Press, 2017. All Rights Reserved. Under the terms of the licence agreement, an individual user may print out a PDF of a single chapter of a monograph in OSO for personal use (for details see http://www.oxfordscholarship.com/page/privacy-policy). Subscriber: Max- 
informed and shaped by that of others. Other animals also learn socially (e.g., Danchin, Giraldeau, Valone, \& Wagner, 2004; Laland, Atton, \& Webster, 2011), acquiring knowledge from conspecifics (Kendal, Coolen, \& Laland, 2009) about, for instance, the best timing, location, and strategies of foraging (e.g., Galef \& Giraldeau, 2001), about mate choice (White, 2004), and about what other species to flee from (Griffin, 2004).

(p.7) The paradigmatic simple heuristic that bets on the behavior of others works as follows (Richerson \& Boyd, 2005):

Imitate-the-majority heuristic: Determine the behavior (e.g., action, judgment, choice, decision, preference, or opinion) followed by the majority of those in your peer group and imitate it.

"Doing as the Romans do when in Rome" makes good sense under a wide range of conditions, but it should not be employed indiscriminately. The majority is not always right: Sometimes it tends toward extreme positions (Isenberg, 1986); sometimes people emulate undesirable and unhealthy behavior from their social network (e.g., overeating; Christakis \& Fowler, 2007); and social information, although easy to acquire, can be less reliable, less accurate, and more outdated than personal information (Kendal et al., 2009). The question of under what circumstances social learning strategies have adaptive advantages over individual learning - that is, what their appropriate contexts are in the social world-goes to the heart of ecological rationality (Todd, Gigerenzer, \& the ABC Research Group, 2012).

Information about others can be exploited using different strategies (for a collection of social learning strategies, see Laland, 2004, Table 1). Instead of "imitate the common type" (Richerson \& Boyd, 2005, p. 120)—a conformist strategy -a human or an animal may rely on another simple heuristic, betting on the behavior of a single model, such as a highstatus or ostensibly experienced and successful individual (Henrich \& Gil-White, 2001):

Imitate-the-successful heuristic: Determine the most successful agent and imitate his or her behavior (e.g., 
action, judgment, choice, decision, preference, or

opinion).

Aficionados of the The West Wing, a television series that from 1999 to 2007 offered a glimpse into the inner workings of a fictional White House, may remember the following exchange. When Josh Lyman, incoming Chief of Staff to the President-Elect, visits C. J. Cregg, Chief of Staff to the outgoing President, Cregg hands him an old sticky note that says "WWLD?" In answer to Lyman's puzzled look, Cregg explains that WWLD stands for "What would Leo do?"-a heuristic she made extensive use of in a setting where trial-and-error learning would have been costly indeed. ${ }^{1}$ Leo McGarry had been the outgoing President's respected first Chief of Staff and a father figure to both Lyman and Cregg. This example illustrates that the imitate-the-successful heuristic (p.8) does not necessarily require observing the model's behavior; it may be sufficient merely to ask oneself what the model would have done. Individuals as well as institutions can keep records of the behavior of efficacious predecessors, allowing others to benefit from their wisdom and success-and their failures-even when direct behavioral observation is not possible. Indeed, foreshadowing more formal analyses, Bandura (1977) suggested that the "more costly and hazardous the possible mistakes, the heavier is the reliance on observational learning from competent examples" (p. 12).

\section{Sharing With Others}

Whether and how resources should be shared with others is a thorny problem for all social creatures. In humans, the sense of having received the "short end of the stick" can trigger powerful negative responses and emotions among strangers (de Quervain et al., 2004), and also among family members, as the biblical story of Joseph attests:

Israel loved Joseph more than any of his other sons, since he was the child of his old age. He made [Joseph] a long colorful coat. When his brothers realized that their father loved him more than all the rest, they began to hate him. They could not say a peaceful word to him.

(Genesis 37:2-5, Revised Standard Version)

In response to their father's favoritism, Joseph's half-brothers sold Joseph into slavery. Sibling rivalry is a ubiquitous phenomenon in family life, although its results are usuallyand luckily - not so dire as in the case of Joseph. Parental

\footnotetext{
Page 8 of 44
} 
resources such as affection, time, and money are limited, and parents with more than one child must decide time and again how to allocate their resources among their $N$ children. How can parents distribute their investment to minimize conflict among and harm to their children? They could rely on a simple heuristic (Hertwig, Davis, \& Sulloway, 2002) that works as follows:

Equity heuristic (1/N heuristic): Invest equally in each of the $N$ children at any given investment period (e.g., day, week, month, year).

Consistent with parents' expressed values in egalitarian societies (for a review, see Hertwig et al., 2002), the equity heuristic ${ }^{2}$ suggests that parents split resources equally among all $N$ children in each (p.9) investment period. This simple heuristic has several interesting properties. By implementing an equal ("fair") allocation of resources, it takes seriously what appears to be a robust and deeply entrenched human aversion to inequality (e.g., Fehr \& Schmidt, 1999; see also chapters 2 and 6). In fact, Fehr, Bernhard, and Rockenbach (2008) recently showed that the tendency to share resources equitably with members of one's own social group appears to emerge in children as young as seven or eight years old. At this age, children strive for an equal distribution of food in situations in which they themselves both could claim a larger share or could hand a larger share to the other party. On the basis of these and other results, Tomasello and Warneken (2008) suggested that the proclivity to share equitably among all members of a group is "characteristic of individuals in the kinds of hunter-gatherer societies in which humans spent the vast majority of their evolutionary history, suggesting that this preference did indeed play an important part in the evolution of human cooperation" (p. 1057).

Another valuable property of the equity heuristic is that it permits those tasked with sharing a resource, such as parents, to justify their allocation decisions to all "stakeholders"; in a family, these include the squabbling children and possibly watchful grandparents. Moreover, the equity heuristic represents a simple distribution principle that has been 
proposed to require less information processing, memory, and effortful calculations than alternatives (e.g., Messick, 1993;

Ohtsubo \& Kameda, 1998, p. 91). Notwithstanding its benefits, the equity heuristic does not guarantee equity in the aggregate, however-an issue we will return to later.

\section{A Vision of Social Rationality}

In this book, we present a vision of social rationality according to which much of reasoning and decision making in humans and animals can be modeled in terms of simple heuristics that neither search, weigh, and add all available information, nor make extensive use of computation to reach optimized solutions to the problems that these agents face. Instead, simple heuristics (also known as fast and frugal heuristics; Gigerenzer et al., 1999) ignore information and eschew computationally extensive calculations and at the same time produce good inferences, choices, and decisions when applied in the appropriate contexts (Todd et al., 2012). Although researchers have argued that the human social world is too complex for heuristics to succeed-a conjecture that we examine shortly-their use appears to be deeply embedded in our collective consciousness. To cite a few literary examples, use of heuristics in social environments has been depicted in Daniel Defoe's Robinson Crusoe (p.10) (1719/1815; see chapter 6) and in diverse passages in the Old Testament, from King Solomon's strategy for inferring which is the true mother of a contested child ${ }^{3}$ (I Kings 3:16-28) to God's test of Abraham's loyalty ${ }^{4}$ (Genesis 22:1-19).

The view that simple heuristics are integral to social rationality stands in stark contrast to an ideal of decision making that George Washington's contemporary Benjamin Franklin (1706-1790), a signer of both the American Declaration of Independence and the United States Constitution, advocated. In a letter to eminent eighteenthcentury scientist Joseph Priestly, a dear friend, Franklin described this ideal:

In the Affair of so much Importance to you, wherein you ask my Advice, I cannot for want of sufficient Premises, 
advise you what to determine, but if you please I will tell you how. [ ... ] My Way is, to divide half a Sheet of Paper by a Line into two Columns, writing over the one Pro, and over the other Con. Then during three or four Days Consideration I put down under the different Heads short Hints of the different Motives that at different Times occur to me for or against the Measure. When I have thus got them all together in one View, I endeavour to estimate their respective Weights; and where I find two, one on each side, that seem equal, I strike them both out: If I find a Reason pro equal to some two Reasons con, I strike out the three. If I judge some two Reasons con equal to some three Reasons pro, I strike out the five; and thus proceeding I find at length where the Ballance lies; and if after a Day or two of farther Consideration nothing new that is of Importance occurs on either side, I come to a Determination accordingly. And tho' the Weight of Reasons cannot be taken with the Precision (p.11) of Algebraic Quantities, yet when each is thus considered separately and comparatively, and the whole lies before me, I think I can judge better, and am less likely to take a rash Step; and in fact I have found great Advantage from this kind of Equation, in what may be called Moral or Prudential Algebra. (1772/1987, pp. 877-878)

Franklin apparently believed that the use of this decision tool is appropriate in many domains-not least in social ones. Indeed, he told a nephew, Jonathan Williams, of his to settle the question of whom to marry using moral algebra; otherwise, he remarked, "I apprehend you will never be married" (Franklin, 1779/1970, p. 282).

Franklin's moral algebra represents a vision of rationality in which the decision maker is expected to abide by two scholarly commandments (Gigerenzer \& Goldstein, 1999; Hoffrage \& Hertwig, 2011): Find all the available information (or if this is not possible, terminate the information search as soon as the costs of further search exceed its benefits), and combine all the obtained pieces of information into one judgment. Modern versions of moral algebra include, for instance, expected utility maximization and game theory in economics; numerous

Page 11 of 44

PRINTED FROM OXFORD SCHOLARSHIP ONLINE (www.oxfordscholarship.com). (c) Copyright Oxford University Press, 2017. All Rights Reserved. Under the terms of the licence agreement, an individual user may print out a PDF of a single chapter of a monograph in OSO for personal use (for details see http://www.oxfordscholarship.com/page/privacy-policy). Subscriber: Max- 
"as-if" theories of human cognition, motivation, and decision making in psychology and cognitive science (e.g., neural networks, Bayesian inference theories); and utilitarian theories in moral philosophy.

Taking aim at the prevailing utilitarianism in ethics, Dennett (1988) criticized his fellow philosophers' complacency toward theories that are divorced from the actual conditions under which people make decisions (see also chapter 17):

For the most part philosophers have been content to ignore the practical problems of real-time decisionmaking, regarding the brute fact that we are all finite and forgetful, and have to rush to judgment, as a real but irrelevant element of friction in the machinery whose blueprint they are describing. (p. 123)

The legitimacy of Dennett's criticism extends beyond philosophy. In his promotion of moral algebra, Franklin largely disregarded the fact that many problems in the social world do not afford us time to ponder the pros and cons of our choices. Similarly, many economists, psychologists, legal scholars, sociologists, behavioral ecologists, and cognitive scientists treat the constraints under which humans and other animals make decisions as negligible influences on whatever part of the cognitive machinery or cultural ecosystem they have been interested in.

In our view, the brute fact that we are all finite-with respect to our time, our information, and our processing powershould be the starting point of our theorizing. We do not claim that under realistic conditions less information and less computation (p.12) will be invariably better than more information and computation. As we already pointed out, the use of social learning strategies is adaptive under many, but not all, circumstances (Kendal et al., 2009). Therefore, our goal in this volume is to investigate how, when, and why simple heuristics can make us smart in a social world that is inherently uncertain and complex, and how, when, and why they fail. Some would challenge-indeed, have challengedour vision of social rationality with the argument that simple heuristics are more likely than not to fail in social domains and that humans would have done better to evolve into a Homo deliberans than a Homo heuristicus. Let us take a closer look at this argument. 


\section{Social and Cognitive Complexity: Forever Entwined?}

Perhaps the most important discovery in research on simple heuristics has been that they can be as accurate as, and sometimes even more accurate than, strategies that make the greatest possible use of information and computation, including optimization models (see Gigerenzer et al., 2011). This finding - namely, that simplicity is not tantamount to sacrificing accuracy-has introduced a new question into the rationality debate: In what environments can a heuristic outperform, say, a logistic regression or a Bayesian model, and in what environments will it lag behind? This question moves the rationality discourse from purely internal consistency considerations to ecological ones.

In a discussion of the right ecology for heuristics, the philosopher Sterelny (2003) has suggested that the success of simple heuristics is likely to be restricted to nonsocial environments:

The decision tasks they [i.e., Gigerenzer and colleagues] typically discuss are not "ecologically valid." We need to see some experimental (or modeling) work on, for example, judgments about whether others are lying to you; on whether others will be reliable partners in cooperative tasks; on whether a partner is engaging in extra-pair copulation. The tasks they discuss rarely involve competitive, interacting, responsive aspects of the environment. (p. 208)

He concluded:

Thus I doubt that rational behavior can be found in "fast and frugal" heuristics. I think it is no accident that the examples of such heuristics in action ignore interactions with other intelligent agents, especially competitive agents. For it is precisely in such situations that simple rules of thumb will go wrong.... Catching a ball is one problem; catching a liar is another. (p. 53)

(p.13) This argument rests on two conjectures, one about complexity and the other about adaptiveness. The first is that environments involving other agents, or social environments, are 
qualitatively different from-specifically, more complex thannonsocial environments. According to the second conjecture, it is doubtful that in the face of this complexity, simple heuristics can give rise to and thereby explain the occurrence of adaptive behavior in social environments. These conjectures are not unique to Sterelny, having similarly been made by other thinkers.

Let us first consider the issue of complexity (see also Hertwig \& Herzog, 2009, and Hurley, 2005).

\section{Are Social Environments More Complex?}

Social environments have often been characterized as "more challenging" (Whiten \& Byrne, 1988, p. 2) and "more intellectually demanding" (e.g., Humphrey, 1976/1988, p. 15) than nonsocial ones. Why? Neuroscientists Seymour and Dolan (2008) spelled out the reasoning:

Choice in social interaction harbors a level of complexity that makes it unique among natural decision-making problems, because outcome probabilities depend on the unobservable internal state of the other individual, which incorporates their motives (intentions). Because most interactions are repeated, optimal learning requires subjects to generate a model of another individual's behavior, and their model of our behavior, and so on. These iteratively nested levels of complexity render many social decision-making problems computationally intractable. (p. 667; emphasis added)

In this argument, social environments are more complex than physical ones because, in them, strategies face counter-strategies, requiring individuals to become proactive interpreters of other agents-in particular, to build a model of others, a model of others' model of them (a "second-order" model), a model of others' secondorder model of them, and so on. Compounding this complexity (and the problem of infinite regress; see Elster, 1986) is the fact that such strategizing individuals cannot base their decisions merely on observable properties (e.g., a rival's body size, whereabouts, and available weapons) but must also consider information that is not immediately detectable in real time (e.g., the rival's alliances with others) or that may be impossible to gauge (e.g., the rival's intentions). Relatedly, in competitive interactions, individuals need to take account of the fact that information conveyed by others can be ambiguous, ephemeral, and even deceptive (Humphrey, 1988/1976; (p.14) Sterelny, 2003), whereas nature, ever dispassionate and amoral, does not strive to outsmart them. 
In one way or another, hypotheses and explanations for the allegedly greater complexity of social than physical environments appear to hinge on two premises. First, the social world requires social animals to be more "political" or Machiavellian than less-social animals (Byrne \& Whiten, 1988; Whiten \& Byrne, 1997). In other words, social environments have put selective pressures on individuals to evolve cognitive competences (e.g., recognition capacities; sensitivity to social information about social rank; detection of third-party relationships; Sterelny, 2003) and strategies (e.g., formation of coalitions and alliances; Harcourt \& de Waal, 1992) that enable them to compete with conspecifics for resources. Second, because of the resulting arms race, encounters with the social world over evolutionary history were (and possibly still are) less predictable than encounters with nature, artifacts, and the rest of the nonsocial world (Whiten \& Byrne, 1988).

Both these premises have been challenged. Gigerenzer (1997), for instance, argued that "complexity comparisons [between social and nonsocial environments] drive us into a conceptual cul-de-sac" (p. 267). One reason is that complexity is a vague term as applied to the social world. To the best of our knowledge, no measure of complexity has been proposed that would allow one to capture the degree of complexity of social and nonsocial environments and make meaningful comparisons between them. Another problem is that, however high or low an environment's complexity (assuming there is such a thing) is per se, not every species perceives and acts on that complexity. What matters is the perceived complexity (or the complexity of the organism's subjective ecology; see von Uexküll's [2001] notion of Umwelt), which, in turn, is a function of the organism's cognitive and sensory machinery. The degree of perceived complexity can hardly explain why a particular level of (social) intelligence is observed in a species, because that perception depends on, or may even be an integral part of, the species' social intelligence.

Despite these objections, let us accept for the sake of the argument the premise that the social world is more complex than the physical world. Does mastering this complexity 
Simple Heuristics: The Foundations of Adaptive Social Behavior

require complex cognition? By extension, are simple heuristics doomed to fail in complex social environments (Sterelny, 2003, p. 53)?

Does Social Complexity Require Cognitive Complexity?

Some have argued that social complexity indeed requires its cognitive counterpart. Humphrey (1988/1976), for instance, argued that social systems have given rise to "calculating beings," who "must be (p.15) able to calculate the consequences of their own behaviour, to calculate the likely behaviour of others, to calculate the balance of advantages and loss" (p. 19). From such assumed abilities, he inferred that "here at last the intellectual faculties required are of the highest order" (p. 19); and Whiten and Byrne (1988) argued that "intellectual capacities adapted to social life may have special and even particularly sophisticated attributes" (p. 2). Humphrey and those who have argued similarly could indeed marshal indirect evidence that is at least consistent with this thesis.

Some of this evidence comes from research on the social intelligence or "social brain" hypothesis (Dunbar, 1998). According to this hypothesis, individuals living in stable social groups face cognitive demands that individuals living alone (or in unstable aggregates) do not, and socially living species should therefore have larger brain sizes than their more solitary congeners. Indeed, Dunbar (1992) observed a strong correlation in primates between the size of the neocortex (relative to the rest of the brain) and mean social group size (see also Shultz \& Dunbar, 2010; and chapter 15), a proxy for social complexity. Dunbar explained this correlation by arguing that the capacity to monitor information about differentiated relationships between individuals within a group should grow with the number of relationships that individuals must track. Reporting correlations between relative brain size and other proxies for social complexity, Dunbar and Shultz (2007) more recently suggested that it is not the computational demands of living in a large group per se, but rather the demands of intense pair-bonding (e.g., close coordination, behavioral synchrony, and the ability to choose

Page 16 of 44

PRINTED FROM OXFORD SCHOLARSHIP ONLINE (www.oxfordscholarship.com). (c) Copyright Oxford University Press, 2017. All Rights Reserved. Under the terms of the licence agreement, an individual user may print out a PDF of a single chapter of a monograph in OSO for personal use (for details see http://www.oxfordscholarship.com/page/privacy-policy). Subscriber: MaxPlanck Society; date: 22 February 2017 
good-quality mates; see chapter 16) that spurred the evolution of unusually large brains in primates. ${ }^{5}$

Let us briefly review the ground covered so far. Some have argued that the social world is more complex than the physical, nonsocial world, and that successful navigation of the social world therefore requires a high degree of cognitive complexity. In this view, simple heuristics simply will not do. As evidence consistent with this argument, proponents could refer to studies showing that, in primates, larger brains are associated with various proxies for a more complex social life. To do so, however, would be to stumble into a number of problems highlighted by Barrett, Henzi, and Rendall (2007), of which we mention two. First, because large brain size is merely a proxy for cognitive complexity, it tells us little about the cognitive mechanisms that actually generate complex social behavior-for instance, whether they are simple heuristics (p.16) or computationally complex strategies. Second, by locating social cognition exclusively in the mind, the equation of social and cognitive complexity overlooks the fact that particular structural regularities in the world can obviate or mitigate the need for complex cognitive processing. The latter argument is central to ecological rationality (Todd et al., 2012): Evolutionary, social, and individual learning can exploit informative environmental structures with specific simple strategies, giving an edge to a decision-making organism that employs those strategies (Todd, Hertwig, \& Hoffrage, 2005). This is not the only reason, however, why cognition in social environments may depend on simple heuristics. It could also be that there are no better alternatives.

\section{Why Simple Heuristics Are Indispensable in a Complex Social World}

In a nutshell, our argument is the following. First, as perceived by humans, the social world is complex (although we consider the claim that the social world is more complex than the physical one to be empty, as long as there is no common metric for measuring environmental complexity). Second, this complexity creates conditions under which optimization is either impossible or inflicts a computational 
burden too heavy to bear. Third, in contrast to Sterelny (2003), Humphrey (1988/1976), and others (but see Hurley, 2005), we argue that simple heuristics can therefore make us smart in the social world-indeed, that they are indispensable to social intelligence.

\section{The Curse of Intractability in Social Environments}

In their portrayal of the social world, Seymour and Dolan (2008) concluded that "these iteratively nested levels of complexity render many social decision-making problems computationally intractable" (p. 667; emphasis added). To illustrate this point, let us turn to chess. A board game with two players, chess offers a choice set of about 30 legal moves (a number that stays more or less constant until the end game) and a time horizon of about 40 moves per player until one party concedes (Shannon, 1950). Given these numbers, $30^{80}$ possible sequences (i.e., about $10^{118}$ ) follow from the original position. Can a human mind evaluate all these consequences? Certainly not. Can the fastest computer do it? The massively parallel IBM computer that beat chess champion Gary Kasparov in 1997, "Deep Blue," could examine some 200 million possible moves per second. How long would it take Deep Blue to generate and evaluate all possible sequences and choose, on the first move, the action (p.17) that maximizes utility? Despite its breathtaking speed, Deep Blue would need some 55,000 billion years to think ten moves by each party ahead-which would not even get it to the end of a typical chess game-in order to pick the best first move (Gigerenzer, 2007). Chess is thus computationally intractable: No large brain or existing machine can find the best (optimal) strategy, even if such a strategy exists.

Relative to real social interaction, chess is a piece of cake. In social interaction, the rules are not necessarily well defined, and players may even renegotiate them depending on how they fare. Moreover, the set of possible actions is vast. Just consider the myriad strategies a child may adopt to prevail in a conflict with a sibling: tell the truth, lie, pacify, accuse, threaten, insult, capitulate, form an alliance, withdraw, throw a tantrum, fight, and so forth. The sibling responds by choosing among an equally long list of possible actions. The

Page 18 of 44 
first child then responds, and so the game unfolds. In light of the vast strategy set, fluid rules, long time horizon, imperfect information, imperfect memory of one's and the other party's actions, and potentially ill-defined or conflicting goals characteristic of human interactions, chess appears simple. If chess is computationally intractable, then so must be social interaction.

Although the "father" of bounded rationality, Herbert Simon, stressed that the human mind "must use approximate methods to handle most tasks" because of its limitations (1990a, p. 6), we do not use heuristics only because of these limitations. Heuristics are often the only recourse when real-world social decision-making problems become computationally intractable, as almost every interesting problem in artificial intelligence is known to be (Reddy, 1988). Chances are, then, that complex social problems with ill-defined rules-such as mate choice (chapter 16)-lie far beyond the reach of optimization. Complexity makes simple heuristics indispensable.

The Curse of Competing Goals in Social Environments Real-world social interactions are often characterized by competing goals. Take, for instance, the career of Alan Greenspan, the legendary chairman of the Federal Reserve, who advised four American presidents for a total of almost 20 years. In his autobiography (2007), he described the recurring conflicts between his professional integrity-that is, pursuing what he considered the right economic policy course (e.g., budgetary discipline) and maintaining the Fed's autonomy in the face of political pressure from the various administrations he consulted-and his private loyalty, as a "libertarian Republican" (p. 238), to his political allies (e.g., members of the George W. Bush administration who pushed for tax cuts).

(p.18) The existence of multiple competing goals or criteria is another major reason why optimization is unattainable in the social world. Without adding burdensome computations to what is already a complex computation (e.g., one would need to combine them in a linear function), one cannot maximize several criteria simultaneously. We propose that the dilemma of competing goals is more pronounced in social than in

Page 19 of 44

PRINTED FROM OXFORD SCHOLARSHIP ONLINE (www.oxfordscholarship.com). (c) Copyright Oxford University Press, 2017. All Rights Reserved. Under the terms of the licence agreement, an individual user may print out a PDF of a single chapter of a monograph in OSO for personal use (for details see http://www.oxfordscholarship.com/page/privacy-policy). Subscriber: Max- 
nonsocial environments. The reason is that the criteria that are often used in nonsocial environments to evaluate decisions and the strategies that produce them, as well as many additional criteria, can be relevant in social environments. In nonsocial environments involving preferential choices between monetary gambles (see Brandstätter, Gigerenzer, \& Hertwig, 2006) or inductive inferences regarding quantities (e.g., Gigerenzer \& Goldstein, 1996), for instance, both internal consistency criteria (e.g., Property $\alpha$; Sen, 1993) and correspondence criteria (e.g., speed, accuracy, robustness; Hammond, 1996) have been used. The same criteria can also be applied in social environments (Sen, 1993). At the same time, myriad other-and genuinely social-criteria can matter in social interactions, such as fairness (e.g., Fehr \& Schmidt, 1999); loyalty (e.g., Kant, 1785/2003); accountability (Tetlock, 1992); trust (e.g., Gambetta, 2009); dependability; unpredictability (e.g., protean behavior; Miller, 1997); autonomy, honor, pride, and face-saving (e.g., Frank, 1988; Nisbett \& Cohen, 1996); consent and equity (e.g., Hertwig et al., 2002); equality (e.g., Messick, 1993); and self-interest. In any given social situation, some of these goals-recall Greenspan's predicament-are likely to compete with others, making optimization an even greater burden.

Parental investment aptly illustrates the dilemma of having competing goals that make optimization even more difficult. One goal espoused by parents in egalitarian societies is fairness, usually interpreted to mean equal distribution of resources among one's children. The equity heuristic, which aims to realize this goal within any given period in the children's development, coincides with the prescription of optimization models in economics and biology in cases in which the expected future "return" on parental investment in each offspring is equal. Yet there is an inevitable downside to this strategy for fairness: Whereas an equity motive produces a fair distribution at any given point in time, it can yield (under plausible assumptions, such as the finiteness of parental resources) an unequal cumulative distribution of investments (for details, see chapter 17). For illustration, consider the allocation of parents' time. Although the heuristic 
guarantees an equal distribution of parental time among children for any given allocation period, the cumulative time distribution will be unequal in families with more than two children (Hertwig et al., 2002; Figure 4). Specifically, middleborns will receive less (p.19) time from their parents than firstborns and lastborns, respectively. The reason is that, unlike their siblings, middleborns never enjoy a period of exclusive attention, always sharing parental resources with at least one sibling. Unfortunately, parents cannot have their cake and eat it, too. They can be fair within any given time interval, or they can be cumulatively fair, making locally unequal allocations of resources. Trying to achieve an optimal tradeoff between inequalities in local and cumulative investment would turn optimization into a nightmare.

In the social world, hierarchies and multiple levels of aggregation and affiliation are pervasive-for instance, people can simultaneously feel strong loyalty to kin, friends, clan, tribe, class, caste, and nation (Richerson \& Boyd, 2005)—as are conflicts between them. As William James (1890) described it: "[A person] has as many different social selves as there are distinct groups of persons about whose opinion he cares.... From this there results what practically is a division of the man into several selves; and this may be a discordant splitting ... " (p. 294). There is no escaping conflicting social allegiances, and there is no escaping conflicting goals in the social world.

\section{The Curse of Incommensurable Reasons in Social Environments}

In March 2011, a dashing and popular politician, Karl-Theodor zu Guttenberg, resigned from his post as Germany's Secretary of Defense amid accusations that he had plagiarized substantial passages of his doctoral thesis. Chancellor Angela Merkel, his boss, stood by him to the end of the furor, arguing: "I appointed Guttenberg as a defence minister. I didn't appoint him as a research assistant or doctoral student or a holder of a degree. I am concerned with his work as defence minister, and he is accomplishing that excellently. That is what counts for me" ("Merkel hält an Guttenberg fest", 2011). Merkel's reasons for defending the minister provoked the moral outrage of more than 60,000 graduate students and scholars in Germany, who sent an open letter to Merkel denouncing her 
continuing support of Mr. Guttenberg for being a "mockery" of all those who "honestly endeavor to contribute to the advancement of science" (http://copy-shakepaste.blogspot.com/2011/02/open-letter-to-chancellor.html). For the letter's signers, scientific integrity is a "sacred" value that cannot be traded off against other reasons for keeping someone in political office. ${ }^{6}$ By weighing ministerial competence against scientific integrity, Merkel became guilty -in the eyes of those irate academics-of what Tetlock, Kristel, Elson, Green, and Lerner (2000) (p.20) called "constitutive incommensurability," in which the mere act of comparison "subverts one of the values (the putatively infinitely significant value) in the trade-off calculus" (Tetlock et al., 2000, p. 854).

According to Tetlock et al. (2000), a sacred value is "any value that a moral community implicitly or explicitly treats as possessing infinite or transcendental significance that precludes comparisons [and] trade-offs" (p. 853, emphasis added). Sacred values are thus rooted in "our commitments to other people" that require us to "deny that we can compare certain things" (p. 854). In the social world, sacred values, and their incommensurability with other considerations, make optimization impossible. The existence of taboo tradeoffs suggests that moral intuitions that guide our social interactions obey simple heuristics for one-reason decision making (see chapter 17).

Summary: Why Heuristics Are Indispensable in a Social World We agree with those who have argued that the social world as perceived by humans can be complex. If chess is computationally intractable, "social chess" is even more so. We ardently disagree, however, with the argument that environmental complexity requires cognitive complexity and therefore makes simple heuristics descriptively and normatively inappropriate models of human cognition in social environments. This argument reflects deeply entrenched intuitions held by many scholars of the mind: The more complex a problem, the more complex the problem solver's cognitive machinery must be to solve it (see Hertwig \& Todd, 2003), and the more complex the problem solver's behavior,

Page 22 of 44 
the more complex the underlying cognitive algorithms must be to explain it. These intuitions overlook at least three important facts and issues. First, mechanistic complexity is not required to produce behavioral complexity. By interacting with properties of the world, simple heuristics can give rise to complex behavior (see Hertwig et al., 2002; and chapter 17). Second, the undisputed complexity of social environments creates the very conditions under which optimization is either impossible or inflicts a heavy and unbearable computational burden. Third, limitations in cognitive capacities (e.g., attention) are not just a nuisance but may reflect an evolved optimal tradeoff across rival adaptive objectives, such as feeding requirements and predator detection (Clark \& Dukas, 2003; Hills \& Hertwig, 2011).

Optimization is feasible, but only in a restricted set of problems and on the basis of simplifying assumptions (Gigerenzer \& Selten, 2001). For Simon (1989), the fundamental question for the study of bounded rationality was: "How do human beings reason when the conditions for rationality postulated by the model of neoclassical economics are not met?" (p. 377). We propose that in social environments (p.21) these conditions are not ordinarily met, for the reasons described above. To navigate in social worlds is to navigate in large worlds (see Binmore, 2009). In a dichotomy proposed by Leonard Savage (1954), the father of modern Bayesian decision theory, large worlds, unlike small worlds, are situations in which one can no longer assume that optimization is possible or that classical models of rationality automatically give a correct answer. In large worlds, the mind cannot help but invoke the humbler competences of a "parts dealer and crafty backwoods mechanic, constantly fixing and redesigning old machines and fashioning new ones out of whatever comes easily to hand" (p. 10), as Wimsatt (2007) described the essence of nature and evolutionary change.

As crafty backwoods mechanics in the social wild, we cannot pretend to be universal, elegant, context-free problem solvers. Instead, as proposed in this book, we rely on simple, versatile heuristics. Like a mechanic, we can repurpose these mental tools and deploy them in new contexts. Admittedly, backwoods

Page 23 of 44 
mechanics are not rocket scientists, but the humble competences embodied in simple heuristics get the job done pretty well.

\section{Why Simple Heuristics Can Flourish in Complex Environments}

Optimization is unworkable as a general tool for decision making under the typical circumstances of the social world. But between a rocket scientist and a backwoods mechanic, there is a wide range of ways for the mind to be. Couldn't and shouldn't people and animals recruit strategies that are more complex than simple heuristics? With his ideal of weighting and adding all reasons for and against a particular choice, Franklin (1772/1987) clearly thought so. Why should decision makers in complex social environments stoop to using simple strategies that explicitly ignore some information and forgo sophisticated processing? The answer is that what has been believed to be a near-universal law of cognition, the accuracyeffort tradeoff, is in fact not universal. This law (e.g., Payne, Bettman, \& Johnson, 1993; Shah \& Oppenheimer, 2008) postulates that humans and animals rely on heuristics because information search and computation cost time and effort, but they do so at the expense of lower accuracy or, more generally, lower performance. Therefore, to make cognition faster and more frugal is to sacrifice accuracy. As has been found in research on fast and frugal heuristics (Gigerenzer et al., 1999; Gigerenzer et al., 2011), however, heuristics can be faster, simpler, and as accurate as-sometimes even more accurate than-strategies that use more information and more computation, including optimization techniques such as Bayesian statistics and neural net (p.22) works. This counterintuitive feat is explained by at least two factors: ecological rationality and exploitation of evolved capacities.

\section{Ecological Rationality}

Using a social analogy to discuss ecological rationality, Brunswik (1957) likened the mind and the environment to a married couple who must come to terms with each other through mutual adaptation. Simon (1990a) offered a nonsocial metaphor: "Human rational behavior (and the rational behavior of all physical symbol systems) is shaped by a 
scissors whose blades are the structure of task environments and the computational capabilities of the actor" (p. 7). By looking at only one of the two blades-that is, the cognitive "software"-one cannot hope to understand why and when a system works. In research on simple, ecologically rational heuristics, considerable progress has been made in identifying environmental structures that are associated with heuristics' success or lack thereof (e.g., Hogarth \& Karelaia, 2005, 2006, 2007; Martignon \& Hoffrage, 1999, 2002; Todd et al., 2012). Although most of these analyses have focused on structures in nonsocial environments, at least three of the key environmental properties identified cut across social and nonsocial environments and thus are likely to have put selective pressure on cognitive adaptations in both types of domains (see Todd et al., 2005). These properties are:

Uncertainty. The degree of uncertainty captures how well a target criterion (e.g., the probability of precipitation tomorrow, or a predator's next move) can be predicted. The greater the unpredictability of the criterion, the more effectively simple heuristics can compete with or even outperform optimization methods in competitions where the criterion can be inferred on the basis of probabilistic cues (e.g., DeMiguel, Garlappi, \& Uppal, 2009; Todd et al., 2012). Ignoring some available information and forgoing complex computation -that is, simplifying-enables the mind to master volatility and uncertainty. This finding clashes with the aforementioned intuition according to which complex social environments necessitate application of complex algorithms. Whiten and Byrne (1988, p. 8), for instance, singled out the predictability, or rather the relative unpredictability, of social criteria (e.g., others' future behavior) as the culprit behind social environments' presumed higher complexity (but see Gigerenzer, 1997). If unpredictability is indeed the culprit, then simple heuristics can be expected to be even more efficient, relative to optimization methods, in social than in nonsocial environments. 
(p.23) Redundancy. Redundancy, which reflects the degree of correlation between distinct environmental cues, can be a boon to simple heuristics that rely on one or few cues (e.g., the take-the-best heuristic; Gigerenzer \& Goldstein, 1996).

Sample size. As the amount of data available to make predictions in an environment shrinks, the advantage of simple heuristics over complex algorithms grows. One reason is that, to make predictions about the future, complex algorithms have to estimate their parameter values on the basis of the data available. Prediction occurs when a model (e.g., a simple heuristic or a statistical algorithm like logistic regression) is used to make statements about events whose actual outcomes have not yet been observed or are otherwise unknown. Fitting, in contrast, occurs when a model's parameters are chosen so that they maximize the fit between the model's predictions and outcomes that are already known.

Humans, animals, and forecasting techniques (for instance, for predicting weather conditions and consumer demand) typically need to predict the future rather than fit the known past and present. In fitting, the more adjustable parameters a model has, the better the model's fit is. In prediction, however, too few or too many parameters can compromise performance (Pitt, Myung, \& Zhang, 2002). This is because, when predicting the future (e.g., how successful a particular child will be in college), a model's adjustable parameters need to be estimated from available data, and the quality of the estimates depends on how large and reliable the data samples are. On one hand, if the sample size is modest, then the deviation between the model's predictions and the true state of nature attributable to variance (sampling error) is likely to be large and will increase with the number of parameters to be estimated. Consequently, a model with many parameters will not generalize well to new situations; that is, it will not be robust. On the other hand, if a model has too few parameters, then the risk is that its bias (lack of flexibility) will drive a wedge between the model's predictions and the true state of

Page 26 of 44 
nature, leading to deviations larger than those attributable to variance (the bias-variance dilemma; Brighton \& Gigerenzer, 2012).

For illustration, consider DeMiguel et al.'s (2009) analysis of the performance of the $1 / N$ heuristic relative to 14 optimal asset-allocation models (including sophisticated Bayesian and non-Bayesian models) in seven investment problems, such as how to allocate money across ten sector portfolios of the Standard \& Poor's 500 (S\&P 500). To estimate the optimizing models' parameters, DeMiguel et al. gave each of them 120 months' worth of asset-return data on the basis of which to predict each portfolio's return in the $121^{\text {st }}$ month. The same procedure was then repeated again and again-in the first repetition, (p.24) by adding the $121^{\text {st }}$ month to the data set, dropping the first month, and predicting the $122^{\text {nd }}$ monthuntil the end of the 120-month-window was reached. The $1 / N$ heuristic, which ignores all previous data, has only one parameter, $N$ (i.e., the number of investment options), which is determined solely by the investment environment.

Notwithstanding the $1 / N$ heuristic's simplicity, none of the complex optimizing models was able to outperform it consistently on established measures of financial performance. To have a fighting chance against the simple heuristic, the optimizing models would have needed much larger samples of stock data-by DeMiguel et al.'s reckoning assuming 50 investment options, 500 years' worth.

Small data samples are likely to be ubiquitous in social and nonsocial environments alike. One crucial reason is that individual learning in both types of environments can be extremely risky. Consider, for instance, cab drivers who must decide whether to pick up a fare. In some cities, misjudging a prospective passenger's trustworthiness can be deadly. According to Gambetta and Hamill (2005), for example, "in the United States a taxi driver is 60 times more likely to be murdered on the job than the average worker," and taxi drivers fall "victim to more deadly violent assaults (184 per $1,000)$ than any other occupation with the exception of police" (p. 1). For novice cab drivers, learning from scratch 
the cues that should raise their suspicion (e.g., a fully zipped, bulky coat) is a risky endeavor.

Although small data samples (or small learning sets) are bad news for complex multiparameter models, information scarcity may trigger the use of simple social learning heuristics that reduce the risk of personal harm by enabling individuals to learn the relevant cues and cue validities from others (chapter 12). As Gambetta and Hamill (2005) observed, learning from one another is one strategy by which cab drivers cope with the dangers of their profession.

\section{Ecological Rationality: A Case Study}

More generally, social learning heuristics are a class of simple strategies about whose ecological rationality we know a lot. Various researchers (e.g., Boyd \& Richerson, 1985; Henrich \& Boyd, 1998; Kameda \& Nakanishi, 2003; McElreath et al., 2005; Rogers, 1988; Sirot, 2001; for reviews, see Kendal et al. 2009; Laland, 2004; Rieucau \& Giraldeau, 2011; see also chapter 14) have proposed formal models specifying appropriate contexts for social learning through imitation, including environments where:

1. The costs of acquiring personal information (e.g., via trial-and-error learning) are extremely high, such as when direct interaction with the physical or social environment can expose the individual to injury and predation risks (recall (p.25) the cab drivers) or when opportunity costs (in lost time and energy) become prohibitively high.

2. Frequent temporal or spatial changes in the environment rob past data of their predictive value (see also the "Uncertainty" section above).

3. Individuals lack relevant prior knowledge (see also the "Sample Size" section above) or are uncertain as to which of several possible behavioral strategies is the most appropriate in the light of available information.

4. Individual information is less reliable than social information. For instance, personal information becomes more error-prone as the heterogeneity of a 
given environment increases, making it more adaptive to learn from others.

Analytical work on social-learning heuristics (including computer tournaments; Rendell et al., 2010) can provide a blueprint for analyzing other important classes of heuristics and environmental properties that determine their success in the social world. Beyond the structures reviewed here, there are many other environmental structures, contexts, and circumstances that are likely to be relevant for understanding the successes and failures of a simple heuristic in a social environment (see chapters 3, 7, 9, 11, and 18). We expect time pressure, for instance, to be a key condition under which good performance requires use of simple heuristics (Rieskamp \& Hoffrage, 2008). Remember the many times at the family dinner table when your mother asked who would like to have, say, the last scoop of ice cream. As we all learned quickly, and sometimes the hard way, there is no time under such circumstances to ponder the alternatives, weighing and adding their costs and benefits. Similarly, many other social decision-making situations-which seat to take in a bus, how to respond to questions in a job interview, whether to approach an attractive person in a bar-require split-second decisions because the environment, made up of other agents and their behavior, changes constantly.

The study of ecological rationality in social environments is rendered all the more fascinating by the fact that the use of a heuristic can rapidly change the very social environment in which it is used, leading to co-evolution of heuristics and environments (Hutchinson, Fanselow, \& Todd, 2012; Todd \& Heuvelink, 2006; and chapter 8). Moreover, a far-reaching implication of the ecological analyses and findings reviewed here is that models of heuristics are not only descriptive. Especially in the large worlds (Savage, 1954) in which optimization is out of reach, they also give important insight into how people should behave given limited knowledge when navigating a complex, uncertain, and fast-paced social (p.26) world (Gigerenzer \& Todd, 2012). In other words, these models have normative power. 


\section{Exploitation of Evolved Capacities}

The second key to the success of heuristics is that they can be masterful exploiters, taking advantage of evolved cognitive, visual, motoric, or other capacities of the mind and body. Evolved capacities represent the ability to do things that people do with ease, such as tracking a moving object against a noisy background (even babies are able to focus their gaze on a moving target and to track an occluded object in their "mind's eye"; see Rosander \& von Hofsten, 2002; von Hofsten, Kochukhova, \& Rosander, 2007), but that robots or computer programs can do only at the expense of enormous computational complexity. Humans need not expend their precious and limited cognitive resources on such tasks, because evolved capacities are typically executed automatically.

Without evolved capacities, heuristics could neither do their job nor be as simple as they are. At the same time, without heuristics, evolved capacities alone could not solve inference, choice, and decision problems. For instance, the recognition heuristic (Goldstein \& Gigerenzer, 2002) and fluency heuristic (Hertwig, Herzog, Schooler, \& Reimer, 2008)—which make inferences about objects based on whether they are recognized, and the speed with which they are recognized, respectively-take advantage of the evolved capacities for recognition memory (e.g., of faces and voices) and systematic forgetting (Schooler \& Hertwig, 2005). The simple tit-for-tat heuristic for making decisions in social exchange situations (see chapter 5)-cooperate first and then imitate your counterpart's last behavior (Axelrod, 1984; Rapoport \& Chammah, 1965) - takes advantage of several evolved capacities, including numerical discrimination (i.e., evaluating whether exchange was equitable), appropriate temporal discounting (i.e., because reciprocity involves paying an immediate cost for future benefits, the benefits must be timediscounted "appropriately for reciprocity to work"; Stevens \& Hauser, 2004, p. 63), and cheater detection (chapter 15). Cheater detection, in turn, appears to capitalize on adaptive specializations for reasoning about social exchange (Cosmides, Barrett, \& Tooby, 2010). Heuristics can afford to be simple because they exploit evolved capacities.

Page 30 of 44 
Evolved capacities represent abilities that can be dedicated to nonsocial domains (e.g., the ability to track an object's movement), social domains (e.g., the ability to feel empathy), or both (e.g., the ability to store and forget information). In our view, the existence of domain-specific capacities is one of the main reasons why dissociations between social and nonsocial cognitive processes can occur in disorders such as autism. Autism has been suggested as resulting (p.27) from the lack of, or delays in, the development of theory of mind, an evolved capacity dedicated to the social world (Baron-Cohen, Leslie, \& Frith, 1985). The existence of domainspecific evolved capacities and deficits therein does not imply, however, that there are two kinds of intelligence, one social and the other nonsocial, composed of qualitatively different cognitive processes. Heuristics that exploit evolved capacities are the common denominator across worlds.

To conclude, contrary to a suspicion still harbored by many social and cognitive psychologists, simplicity in cognitive mechanisms does not open the floodgates to irrationality (see Krueger \& Funder, 2004) or to other horrors named (e.g., loss of money) and unnamed. Nor do heuristics capitulate in the face of complexity, uncertainty, scarcity of information, or time pressure. They are the indispensable tools that the mind -that parts dealer and crafty backwoods mechanic-can recruit to find solutions to intractable problems in a complex and uncertain world. By exploiting the evolved capacities that the mind has at hand, the heuristics can stay fast and frugal. They are not foolproof, though. They will lead to good-or at least satisficing (Simon, 1956, 1982, 1990a)—solutions to the extent that they are employed in the right environments. How people learn, individually and socially, to use heuristics in an adaptive way is one of the central questions for future research in this area (for a start, see Rieskamp \& Otto, 2006). Before the question of how heuristics are used, however, comes the question of what heuristics are used. Let us emphasize that although we focus on the limits of optimality modeling throughout this chapter, the optimality approach can still help us in various ways-for instance, by suggesting what heuristics people and animals may use (see Hutchinson \&

Page 31 of 44 
Gigerenzer, 2005) and by providing us with benchmarks for heuristic performance.

The Adaptive Toolbox: Heuristics in Games Against Nature and Social Games

Like Gigerenzer et al. (1999) and Gigerenzer and Selten (2001), we refer to the mind's inventory of heuristics, the building blocks they are made of (e.g., aspiration levels, search rules, emotions), and the evolved capacities that they co-opt (e.g., depth perception, face recognition) as the adaptive toolbox. The adaptive toolbox is called on to perform in two very broad domains, games against nature and social games. "Games against nature" refers to situations in which a person needs to predict or outwit nature to perform ancestral tasks and modern equivalents thereof, such as foraging for food and then navigating home; boosting the yield, quality, and value of crops; identifying a good enough location for one's camp; mastering hard-to-predict or unpredictable hazards (e.g., lightning, earthquakes, fires, drought, (p.28) avalanches); exploring unknown or challenging terrains (e.g., mountains, lakes, rivers, deserts); fighting diseases that kill livestock and people; and playing games of solitary skill (e.g., holing a putt in golf, climbing the tallest buildings of the world; Collins, 2009). The outcome a person experiences in these games is determined jointly by her decision and the true state of nature.

In social games, in contrast, how well a person fares does not depend on a dispassionate other such as nature, but on the decisions of other self-interested players. According to game theory, each player in a social game desires to maximize expected utility, where expectation is based on the probability distribution that represents the player's uncertainty about the other players' decisions (von Neumann \& Morgenstern, 1944). The litmus test for the players' economic rationality is the Nash equilibrium condition: In equilibrium, each player makes decisions that are optimal given the equilibrium decisions of others, and no player has an incentive to change his strategy. More generally, in a social game, what strategy is adaptive for one player depends on the strategy used by others (and vice

Page 32 of 44

PRINTED FROM OXFORD SCHOLARSHIP ONLINE (www.oxfordscholarship.com). (c) Copyright Oxford University Press, 2017. All Rights Reserved. Under the terms of the licence agreement, an individual user may print out a PDF of a single chapter of a monograph in OSO for personal use (for details see http://www.oxfordscholarship.com/page/privacy-policy). Subscriber: Max- 
versa), whereas in a game against nature, what strategy is adaptive depends on the state of a disinterested agent. Although we honor this classic distinction, we will interpret the domain of social games as including not only decisions (e.g., whether or not to cooperate), but also judgments (e.g., about where a person lives), estimates (e.g., what is a person's mate value), and categorizations (e.g., whether a person belongs to a hostile tribe) of social entities. These processes may be totally independent of the other player's decisions; yet we treat them as belonging to the domain of social games because they can be subservient to decisions in those games.

Although games against nature and social games represent distinct domains, the aforementioned challenges that decision makers face-among them intractability, time pressure, information scarcity, and dynamically changing environmental circumstances-cut across the two types of domains, and simple heuristics offer solutions to problems in both types. This does not mean, however, that exactly the same heuristics will be employed to play both types of games, although some heuristics do travel between the domains. We propose that the adaptive toolbox encompasses at least four classes of heuristics, depending on whether they feed on social, nonsocial, or both kinds of information, and whether they can be employed in games against nature or social games, or both. Social information is information concerning the state of a social being or a social system (e.g., behavior, intentions, properties); nonsocial information is information concerning the state of a physical entity or system. The four classes of heuristics are shown in Figure 1-1. (p.29) 


\author{
Heuristics \\ Bound to \\ Games Against \\ Nature \\ The first class \\ encompasses \\ heuristics \\ that can be \\ fed only \\ nonsocial \\ information \\ and that aim \\ to infer \\ criteria that \\ are nonsocial \\ in nature \\ (Figure 1-1, \\ Panel A). A \\ prototypical \\ game against \\ nature is \\ weather \\ forecasting. Both ancient and contemporary practitioners have \\ relied on heuristics to play this game. A well-known rule of \\ thumb from ancient times, with variations in several European \\ languages, goes: "Red sky at night, sailors' delight. Red sky at \\ morning, sailors take warning." Here red refers to the glow of \\ the morning or evening sky caused by haze or clouds related \\ to storms in the area. In Gujarat (India), farmers try to predict \\ the monsoon's timing and character using an ancient and \\ apparently reasonably accurate rule of thumb that predicts the \\ monsoon will begin one-and-a-half months after the blooming \\ of the Cassia fistula tree, a common species on roadsides in \\ the region ("Folk Wisdom," 2001). Modern weather \\ forecasters "often develop rules of thumb to adjust the \\ guidance produced by NWP (numerical weather prediction) \\ models" as well (Hamill, 2003, p. 933). That is, they use \\ heuristics to handle the complex outcomes of highly \\ sophisticated number-crunching forecast models. One example \\ of such a heuristic in shorter-range forecasts is " $d$ (prog)/dt." \\ By this rule of thumb, if the forecasts (of (p.30) a set of lagged
}

\footnotetext{
Page 34 of 44
}

PRINTED FROM OXFORD SCHOLARSHIP ONLINE (www.oxfordscholarship.com). (c) Copyright Oxford University Press, 2017. All Rights Reserved. Under the terms of the licence agreement, an individual user may print out a PDF of a single chapter of a monograph in OSO for personal use (for details see http://www.oxfordscholarship.com/page/privacy-policy). Subscriber: MaxPlanck Society; date: 22 February 2017 
Simple Heuristics: The Foundations of Adaptive Social Behavior

forecasts from the same model) show a trend, "this trend is more likely than not to continue" (Hamil, 2003, p. 933).

Heuristics That Can Travel Between Worlds

Heuristics in the second class shown in Figure 1-1 (Panel B) are able to cross the border between games against nature and social games. Their versatility stems from their ability to work with both social and nonsocial information, and the criteria of interest may concern social or nonsocial entities. Resource-allocation heuristics such as the $1 / N$ heuristic, for example, are versatile enough to be employed in both worlds. $N$ can stand for the number of investment options (DeMiguel et al., 2009), the number of players in the ultimatum game (Güth, Schmittberger, \& Schwarze, 1982; chapters 2 and 6), or the number of children in a family (Hertwig et al., 2002).

Another example of a heuristic in this class is the gaze heuristic (Gigerenzer, 2007), a rule of thumb that experienced ball players appear to use-not necessarily consciously-to catch a ball that is already high in the air:

Gaze heuristic: Fixate your gaze on the ball, start running, and adjust your running speed so that the angle of gaze (i.e., the angle between your eye and the ball, relative to the ground) remains constant.

It is worth noting that the task of predicting the trajectory of an airborne ball is, at least in theory, tremendously complex (Dawkins, 1989), and using an optimization procedure would lead to a computational explosion that could not be handled in real time. A player who takes advantages of the gaze heuristic, however, can ignore the myriad causal variables (such as initial distance, velocity, angle, speed, wind, and spin) that would have to be gauged and integrated to compute the ball's trajectory. The heuristic exploits the fact that all the relevant information is captured by a single variable: the angle of gaze. Sailors and pilots use similar heuristics when trying to evade collisions, as do dogs trying to catch a Frisbee (the LOT heuristic; Shaffer, Krauchunas, Eddy, \& McBeath, 2004). Maintenance of the optical angle appears to be used not only in the interception of inanimate objects (games against nature), but also in the pursuit of prey (social games). Bats, birds, and dragonflies, for instance, have been found to maintain a constant optical angle between themselves and their prey (see Shaffer et al., 2004; chapter 15). Prey such as moths appear to

Page 35 of 44

PRINTED FROM OXFORD SCHOLARSHIP ONLINE (www.oxfordscholarship.com). (c) Copyright Oxford University Press, 2017. All Rights Reserved. Under the terms of the licence agreement, an individual user may print out a PDF of a single chapter of a monograph in OSO for personal use (for details see http://www.oxfordscholarship.com/page/privacy-policy). Subscriber: MaxPlanck Society; date: 22 February 2017 
thwart predators' use of the gaze heuristic by tumbling and looping unpredictably when hit by bat ultrasound (signaling the approach of a predator) -an instance of protean behavior (Miller, 1997). (p.31) A final example of a border-crossing heuristic is takethe-best (Gigerenzer \& Goldstein, 1996). Taking social or nonsocial information as input, take-the-best infers which of two alternatives has a higher value on a criterion on the basis of binary cue values retrieved from memory. The criterion can be social or nonsocial in nature. It works as follows:

Take-the-best heuristic: Search through cues in order of their validity. Stop when the first cue that discriminates between the alternatives is found. Infer that the alternative with the positive cue value has the higher value on the criterion.

Take-the-best can be employed to predict the relative rainfall on two days from cues such as the percentage of cloud cover and types of clouds. Or it can predict the high school dropout rate in Chicago's public high schools from cues such as a school's percentage of students from low-income families and average Scholastic Aptitude Test (SAT) scores (Czerlinksi, Gigerenzer, \& Goldstein, 1999). The heuristic also describes how expert burglars decide which of two residential properties is safer for a burglary (Garcia-Retamero \& Dhami, 2009) on the basis of, among other cues, social information such as whether the property is cared for and whether somebody seems to be at home (lights on or off, letterbox emptied or not).

Heuristics That Can Travel Across Worlds but Require Social Information

A third class of heuristics can be used in games against nature (e.g., finding routes to foraging sites) as well as social games (e.g., learning female mating preferences) but require specifically social input (Figure 1-1, Panel C). Perhaps the most paradigmatic examples in this class are heuristics such as the imitation heuristics described earlier that acquire information from others, or copy the behavior of others, or both. But even when no one else is present, a person can benefit from social information-for instance, by calling up the memory of others' behavior in the same or similar situations or by consulting cultural memory (e.g., books, the Internet).

Page 36 of 44 
Another set of heuristics that can cross borders is group decision rules (e.g., Hastie \& Kameda, 2005). Once these heuristics have received their social input-the opinions ("votes") of a collection of people or animals (for the use of quorum rules in ants, honeybees, and other animals, see Pratt, Mallon, Sumpter, \& Franks, 2002; Seeley \& Visscher, 2004; Passino, Seeley, \& Visscher, 2008; Conradt \& Roper, 2005)— they can help the user navigate natural or social environments. For instance, the explorer William Clark, who was recruited to explore the Northwest Territory and claim it for the United States in the early nineteenth century, had everyone (p.32) in the expedition, including servants and native guides, vote on what strategy to use in a game against nature; namely, where to locate his winter camp. According to Hastie and Kameda (2005), he then used the following rule (in Hastie \& Kameda, 2005) to aggregate the votes:

Majority heuristic (rule): Each member of the group assigns one vote to the alternative (e.g., location) with the highest estimated value, and the alternative receiving more than half of the votes is chosen.

Investigating the ecological rationality of the majority heuristic in truth-seeking contexts (i.e., where an objective truth criterion exists), Hastie and Kameda concluded that the majority rule (choosing the alternative with more than half of the votes) and the plurality rule (choosing the alternative with most votes) "fare quite well, performing at levels comparable to much more resourcedemanding rules" (p. 494) across a wide range of environmental variations.

\section{Heuristics Bound to Social Games}

Heuristics in the fourth and final class require social input and are applicable only in the domain of social games (under our wider definition thereof; Figure 1-1, Panel D). A prototypical example is the aforementioned tit-for-tat heuristic: Cooperate first, and then imitate your counterpart's last behavior (Axelrod, 1984). Tit-for-tat cannot be applied in games against nature, nor can related strategies such as "generous" tit-fortat (which, unlike tit-for-tat, forgives occasional defection; e.g., Nowak \& Sigmund, 1992; Wedekind \& Milinski, 1996) and the various cooperation heuristics investigated in chapter 5. 
The social information required by heuristics in this class ranges widely. For the circle heuristic (Snook, Taylor, \& Bennell, 2004), it is the locations of crimes committed by a serial killer; for the hot-hand heuristic (Bennis \& Pachur, 2011; Burns, 2004), the previous high scores of an athlete in a team sport such as basketball or soccer; for the hiatus heuristic (Wübben \& von Wangenheim, 2008), the length of a customer's inactivity; and for the default heuristic (Johnson \& Goldstein, 2003; McKenzie, Liersch, \& Finkelstein, 2006), the existence of an implicitly recommended policy default. Heuristics can also be restricted to application in social games by virtue of co-opting evolved social capacities such as the ability to trust (chapters 3,5 ), the ability to sense social emotions (e.g., honor; Frevert, 1995), and the ability to take another person's perspective (Hurley, 2005; chapter 2).

Like every taxonomy, our taxonomy of heuristics is not perfect, and some heuristics could be assigned to more than one category (p.33) (e.g., the Pavlov heuristic, which can outperform even tit-for-tat in the Prisoner's Dilemma; Nowak \& Sigmund, 1993; Wedekind \& Milinski, 1996). It highlights, however, that as mental tools heuristics are as integral to social intelligence as they are to the intelligence that is brought to bear in dealings with nature; or in Frith and Frith's (2010) words: "We should, perhaps, not be surprised that cognitive processes that have evolved for nonsocial purposes can readily be co-opted for social purposes by natural selection" (p. 742).

\section{Intuitive Design}

Identifying models of heuristics that can describe a wide variety of human decision making in social (and nonsocial) environments could easily be an end in itself, but it is more than that. Models of heuristics are meant to describe actual decision processes, not only observable outcomes. As such, they can inform social engineering aimed at improving decision making in important domains of life such as healthcare, law, and business, both at the process and at the outcome level. 
Optimization theories such as Bayesian expected utility maximization, cumulative prospect theory, and the inequity aversion model typically entail complex estimations and computations. One reasonable interpretation is therefore that these models are as-if models that capture behavioral outcomes, not the cognitive processes producing those outcomes. Nobel Prize laureate Milton Friedman (1953a) famously defended as-if theories in economics and beyond by arguing that a theory ought to be tested by the accuracy of its behavioral predictions and not by the "realism" of its almost certainly false assumptions (e.g., the assumption that economic actors behave as if they were fully informed and unconstrained by capacity limits). That is, the causal mechanisms that actually govern behavior lie outside the realm with which Friedman's advocated approach, known as positive economics, is concerned.

We agree with those who think that Friedman got it wrong (see Boylan \& O'Gorman, 1995). By giving up on the study of causal processes, Friedman abandoned an important lever of control in efforts to engineer processes and environments in ways that change decision making for the better. Intuitive design (Gigerenzer et al., 2011, p. xix) describes the explicit goal of using what we know about heuristic decision making (bounded rationality) and about the match between mind and environment (ecological rationality) to improve public welfare.

The cliché opening sentence in articles on human decision making is that each of us makes thousands of decisions every day. Depending on how one defines decision, this may be an accurate statement (e.g., (p.34) according to Wansink \& Sobal, 2007, people make more than 200 food-related decisions daily). But there is not only an art to making (so many) decisions; there is also an art to not making them. We sidestep making decisions by, for instance, letting others or the environment decide for us, or simply by doing nothing. But what situations and environments are likely to trigger such decisional abstinence? Legal defaults represent one such environment (Sunstein \& Thaler, 2003). Using the default heuristic- "If there is a default, accept the implicit policy recommendation and adopt it"-people avoid making an active 
decision. The fact that accepting a default requires no effort may explain some of its appeal. Another consideration, however, is that decision makers appear to understand defaults as a communicative act by which policymakers convey a recommended course of action (McKenzie et al., 2006). The default heuristic thus epitomizes a case in which, following the "Simon's scissors" principle, behavior is jointly determined by the mind (the heuristic) and the environment (the policy default).

Policymakers can take advantage of reliance on the default heuristic to foster public goods (e.g., organ donation; see chapter 17 and Johnson \& Goldstein, 2003) or desirable behavior such as the public's use of renewable energy. In Schönau, Germany, 99\% of households have stuck with the town's default option of using "green" electricity, even though the public referendum to adopt this default was supported by only a small margin (52\% of residents in favor versus $48 \%$ against, with $90 \%$ of voters participating; Pichert \& Katsikopoulos, 2008). Heuristics that involve copying others' behavior can also be used to promote environmentally friendly behavior. In a study conducted in an actual hotel, the (accurate) message that a large majority of the hotel's guests chose to reuse their towels prompted more other guests to follow suit than did a message focusing guests' attention on the importance of environmental protection and towel reuse without mentioning what most other guests do (Goldstein et al., 2008).

Information about what others do is increasingly widespread. Internet retailers such as Amazon tell customers who view a specific item what other customers who bought this item also bought. But this is just the beginning. With the rapidly emerging "internet of things" (Fleisch, 2010) and "ubiquitous computing" (Greenfield, 2006)-the notion that virtually every physical thing in the world, from clothes to shower stalls, can feature tiny and inexpensive low-end computers and thus become sites of processing-we are experiencing a feedback revolution. For instance, with "smart" power outlets and meter-based applications on mobile phones, people are already able to receive real-time feedback on their energy

Page 40 of 44 
consumption, not only overall, but by device (Weiss, Loock, Staake, Mattern, \& Fleisch, 2010). To fully exploit the potential (p.35) of this revolution, the feedback environment must be designed with a clear idea of how one wants to influence deployment of the cognitive blade of Simon's scissors. For instance, depending on what behavior is to be fostered and what information is most apt to prompt imitation, people may be given feedback about other households' average consumption, similar households' consumption, or the consumption of the most energy-efficient household, as well as concrete behavioral recommendations for changing their consumption patterns.

We believe that intuitive design represents an opportunity for psychologists and, more generally, scholars of the science of heuristics to participate in the engineering of environments and heuristic-and-environment interactions for the benefit of individuals and society as a whole.

\section{Summary of Our Vision of Social Rationality}

This book is about simple heuristics for making decisions in a social world: how they work, and when and why they succeed or fail. We show how simple heuristics can be an essential tool for navigating the complexities and vagaries of social environments. These heuristics are descriptive models of organisms' behavior under the real-world constraints of limited time, computational capacity, and knowledge. Their impressive performance poses a normative challenge for models based on complex calculations and, we hope, will spur a debate on the nature of social rationality. The research program presented here can be summarized by the following theses:

1. As perceived by the human mind, the social world (Umwelt) is complex, but not necessarily more complex than the nonsocial world.

2. However complex the social world may be, its complexity does not require cognitive complexity; rather, it entails conditions that make simple heuristics indispensable, such as intractability, multiple competing goals, and incommensurable reasons. 
3. Much of reasoning and decision making occurring in human and animal social environments can be modeled in terms of simple heuristics.

4. Although simple heuristics forgo extensive information-search and complex calculations, they can be as accurate and even more accurate than more complex strategies and can be used to reach other goals that are valued in social environments (e.g., transparency, fairness, speed).

(p.36) 5. Heuristics can be simultaneously successful and simple by co-opting evolved capacities. The capacities themselves can represent complex adaptive specializations (such as memory, movement tracking, and empathy).

6. Simple heuristics per se are neither rational nor irrational. Their rationality is ecological. In other words, heuristic performance depends on the match between the architecture of the heuristic and the structure of the environment in which it is used. 7. Heuristics' simplicity inoculates them against overfitting and enables them to achieve robust performance given small samples of information. 8. Simple heuristics can model adaptive decision making both in games against nature and in social games. In this sense, there is no social intelligence distinct from nonsocial intelligence.

9. Simple heuristics are tools of moderate generalizability. Some can be used only in games against nature, whereas others are restricted to social games. Still other heuristics can be applied in both types of games.

10. Shedding light on the adaptive toolbox of simple heuristics used to navigate social environments-in particular, characterizing their strengths and weaknesses-can help us design environments and heuristics in ways that improve public welfare.

Having offered a variety of strong arguments, bold speculations, and sweeping claims in this introduction, we would like to conclude on a note of humility. There are many interesting and important things that we have not achieved or

Page 42 of 44

PRINTED FROM OXFORD SCHOLARSHIP ONLINE (www.oxfordscholarship.com). (c) Copyright Oxford University Press, 2017. All Rights Reserved. Under the terms of the licence agreement, an individual user may print out a PDF of a single chapter of a monograph in OSO for personal use (for details see http://www.oxfordscholarship.com/page/privacy-policy). Subscriber: Max- 
even attempted in our explorations of social rationality so far. For instance, one obvious area of uncharted territory in this book is the role of moral emotions or, more generally, social emotions, which can be seen as evolved capacities on which simple heuristics can draw. Moral emotions such as shame, guilt, embarrassment, pride, and gratitude (Tangney, Stuewig, \& Mashek, 2007) and social emotions such as love and jealousy (DeSteno, Valdesolo, \& Bartlett, 2006) have been shown to facilitate fast and frugal decision making by limiting or stopping information search, constraining choice sets, or obviating cost-benefit calculations (Fessler, 2001; Frank, 1988). Clearly, our journey through the wilderness of social rationality is far from over. We hope you will come and join the expedition.

Notes:

(1.) Among Christian believers, this heuristic has sometimes taken the form of asking oneself "What would Jesus do?"

(2.) In research on distributional justice, equity and equality describe two distinct allocation principles (Deutsch, 1975). Like Hertwig et al. (2002), we use the terms interchangeably here, in accord with the most common meaning of equity in everyday language; namely, the quality of being equal or fair.

( ${ }^{3}$ ) Two women came before Solomon, King of Israel, to resolve a quarrel about which of them was the true mother of a particular baby. Solomon applied a simple heuristic: "If a woman puts her own interest over the life of her professed child, then she cannot be the child's mother." Specifically, he proposed to cut the (living) baby in equitable parts, so as-in a macabre variation on the equity heuristic-to give each mother her "fair" share. Solomon's intuition was that the true mother would rather give up the baby than sacrifice its life. The king therefore declared the woman who preferred to relinquish the baby to be its true mother and returned it to her.

(4.) Interestingly, even God-though often depicted as omniscient (Psalm 147:4, 5; Acts 15:18)-turns to heuristicbased inference. To test Abraham's devotion to him, he uses a policy that can be summed up as follows: "If a man is willing at

Page 43 of 44 
my command to sacrifice what is dearest to him, his faith is beyond doubt." Specifically, God demands that Abraham sacrifice his only son, Isaac. Just as Abraham is about to comply, God stays the execution: " 'Do not lay a hand on the boy,' he said. 'Do not do anything to him. Now I know that you fear God, because you have not withheld from me your son, your only son' " (Genesis 22:12). Such tests are common in groups and organizations in which loyalty is of paramount importance. To take a decidedly unholy example, would-be mafiosi may be required to "whack" (kill) someone as a test of their commitment and as insurance against infiltration by undercover agents (Gambetta, 2009).

( ${ }^{5}$.) Because the number of possible relationships is constrained by the number of animals in the group, there is a positive relationship between group size and brain size.

(6.) Unlike the general public, Merkel cannot have been a stranger to this ethos, as she is a trained scientist with a doctorate in physics.

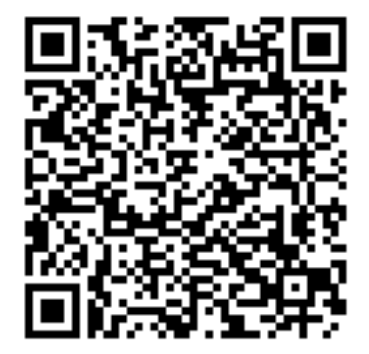

\section{Access brought to you by: Max-Planck Society}

